\title{
Libro: Educar al nuevo príncipe: ¿asunto racial o de ciudadanía?
}

Diego H. Arias Gómez ${ }^{1}$

El texto Educar al nuevo príncipe: ¿asunto racial o de ciudadanía?, escrito por Martha Cecilia Herrera (2013) y editado por la Universidad Pedagógica Nacional presenta al público lector una arista muy interesante sobre la configuración de la cultura política en Colombia a principios del siglo XX. El objetivo de esta publicación es ubicar las representaciones más destacadas que circulaban en la sociedad colombiana, respecto a la ciudadanía y al tipo de sociedad deseadas, a propósito de las tensiones y los conflictos entre intelectuales en el contexto de la modernización y urbanización crecientes en la nación. En concreto, la autora establece una rigurosa relación entre la educación y el proyecto capitalista de dicha época en Colombia, cuando el afán por la homogenización de la población y la unificación del Estado son patentes. De ahí el sugestivo título de la obra, Educar al nuevo príncipe, pues al calor de la Revolución francesa se entendió que el pueblo y su derecho a la ciudadanía vendrían a reemplazar la majestad del antiguo príncipe del régimen monárquico, asunto que en el escenario colombiano estuvo cruzado por determinismos geográficos, raciales y morales que le dieron un horizonte particular a la idea del buen ciudadano. Las fuentes principales usadas por la autora fueron publicaciones periódicas como revistas y prensa, textos de diversa índole de destacados intelectuales y documentos de política pública.

El libro se divide en tres grandes capítulos. En el primero, "El entramado del imaginario nacional: raza y nación", se profundiza en ciertos conceptos básicos relacionados con la construcción de nación en Occidente y la importancia en esta tarea de la educación pública y ciudadana; adicionalmente se expone la relevancia del pensamiento de la élite, encabezada en periodistas, literatos, abogados y políticos profesionales especialmente, respecto a la configuración de la nación en Colombia y la trascendental importancia del asunto racial e higienista en este proceso. En este mismo apartado Martha Cecilia analiza las particularidades sobre el tratamiento del tema racial en el espacio escolar, la mayoría de las veces como añoranza a la tradición hispanista y de desprecio a lo mestizo, lo negro y lo indígena. Para la autora,

[...] lo que está en discusión es la acepción de raza como noción abstracta y su manera de equipararse a la nación y por lo tanto al pueblo, eufemismo tras el cual se esconde el debate sobre la participación social 
y política, y sobre el derecho a la ciudadanía de la mayoría de la población colombiana. Esta última, en lugar de ser mirada como sujeto político en igualdad de condiciones, es representada como un calidoscopio que agregó a la discriminación social y a la marginación política, las tensiones derivadas del color de la piel (p. 72).

El segundo capítulo, titulado "Ser colombiano, una categoría de dignidad", se centra en la concepción de educación divulgada desde el poder; primero para ofrecer las versiones oficiales respecto a lo que significaba educar al pueblo, aquí la educación se presentaba como la mediación del vínculo social con la nación, y también como instrumento de control social para legitimar el establecimiento. Este capítulo, más adelante retoma el concepto de dignidad como supuesta categoría clave de la colombianidad, pues esta condición decorosa se postuló como el ideal de un carácter y un modo de comportamiento ajustado a ciertos patrones estéticos e higiénicos. Al final del capítulo se plantean los escenarios propios del modelo en ciernes, en el que la arquitectura urbana, las campañas de lectura, la censura a al consumo de la chicha y el rol de la Radiodifusora Nacional de Colombia, lograron un lugar destacado.

El tercer y último capítulo, "La escuela como proyecto nacional", aborda los mecanismos y esfuerzos de moralización de la infancia del país en la primera parte del siglo $X X$, desde la mirada de la regulación del comportamiento y el dominio de sí, en el marco del ethos que la élite imponía. Para la autora, "la moralización, no solo de la población en general, sino, específicamente de la infancia, va a ser una de las estrategias claves para garantizar el cambio de patrones culturales en la mayoría de la población y uno de los objetivos centrales de las políticas públicas" (p. 120). Además se destaca, durante el periodo en cuestión, la escuela defensiva, entendida como aquella preocupada por vigorizar fisiológicamente al futuro ciudadano en tres campos de acción: el individuo, la raza y el territorio. De acuerdo con los datos suministrados es posible identificar que los intelectuales de la época vieron la escuela como un mecanismo de resurrección racial y de moldeamiento de la esencia colombiana. Este capítulo avanza con la exposición del imaginario de la escuela como formadora de conciencia política, el distanciamiento de proyectos políticos internacionales y, finalmente, a tono con el carácter complejo de cualquier cons- 
trucción social, destacando la presencia de algunas resistencias a la defensa de escuela como proyecto nacional.

Además del recorrido por el contenido de la obra, vale la pena destacar algunos aspectos importantes, ciertas ideas/fuerza que pueden servir como categorías analíticas para la investigación en historia cultural, y que Martha Cecilia ha utilizado en esta producción con formidable destreza.

- El papel de las élites y el Estado es determinante en la configuración de imaginarios sociales. La investigación histórica de la profesora Herrera, plasmada en el presente texto, presenta con solvencia conceptual el protagonismo de numerosas personalidades, en relación orgánica con el Estado, al momento de reconocer el proyecto de nación como una formación social específica.

- El poder no es monolítico, existen pujas por imponer significados. El texto muestra cómo la ciudadanía en Colombia es un formidable ejemplo de cómo grupos del poder han impulsado un modelo de sujeto y subjetividad funcional en determinado tipo de sociedad. Ello se expresa en la movilización de ingentes recursos culturales para circular saberes sobre el deber ser del ciudadano en formación, por parte de la dirigencia de la época.

- Las influencias ideológicas internacionales son claves para entender el pensamiento criollo. Especialmente producciones de Europa y Estados Unidos han sido trascendentales para entender gran parte de la dinámica de las ideas en Colombia, bien como adaptación, apropiación u oposición. Ello explica coincidencias plasmadas en el libro Educar al príncipe, en cuanto a proyectos de nación, con algunos países del continente, como el caso de la raza y la higiene en tanto modelos de ciudadanía y escuela.

- Existen apropiaciones dispares, fragmentadas y localizadas de las pretensiones oficiales. Los discursos hegemónicos no siempre se imponen con éxito en la población, es decir, los padres de familia, la Iglesia y los maestros se convirtieron muchas veces en obstáculo para la materialización de sus presupuestos durante la primera parte del siglo XX. Además, la importancia y diferenciación de 
lo regional, en Colombia, hizo mucho menos homogéneas las políticas de educación ciudadana.

- El pensamiento dominante muchas veces es asumido por la oposición. La comprensión de actores sociales, en periodos históricos acotados y en sus posibilidades concretas de realización, permiten entender que los discursos de la élite fueron avalados por los movimientos sociales de resistencia, sin renunciar a sus principios o a su proyecto social, como sucedió con la iniciativa racial e higienista impulsada por el poder y respaldada por organizaciones gremiales de docentes y grupos de izquierda.

- Son muy importantes las lecturas de larga duración. La doctora Martha Cecilia ofrece una interpretación que trasciende las aparentes diferencias políticas de los gobiernos, lo que permite identificar constantes y tendencias pese a estar la dirigencia liberal o conservadora en la primera parte del siglo XX, y más bien leer los cambios como el reacomodo del país un capitalismo industrial en formación.

- La escuela y la educación son escenarios privilegiados de la política. Las más de doscientas páginas, resultado de la investigación, confirman la profunda relación entre educación y cultura política, ya que la primera, en tanto dispositivo de poder, ha sido una trinchera social privilegiada para forjar proyectos de nación y moldear determinados tipos de ciudadanía en Colombia. Práctica que ha operado por múltiples vías, como la escuela pública, los medios de comunicación y otros escenarios de la cultura. Investigaciones como la presente confirman que los esfuerzos pedagógicos de las élites han desbordado los espacios escolares y que su eficacia reposa en la capacidad de permear muchos escenarios sociales.

- El análisis de la historia social es reflexivo. Martha Cecilia propone afirmaciones abiertas, indica tendencias con cautela a partir de la información encontrada, sin generalizaciones cerradas, y reconoce que al pasado 
se accede por vías parciales proclives de ser complementadas con otras investigaciones y nuevas miradas.

- Por último, la política pasa por el cuerpo. El texto Educar el nuevo príncipe: ¿asunto racial o de ciudadanía? demuestra que la política, en tanto proyecto de configuración del orden deseado, está marcada por deliberadas lógicas que prescriben los cuerpos deseables y deseados; los políticos dedican esfuerzos para que su idea de ciudadanía tenga cuerpo, comportamiento, deseo, pensamiento y acción. La educación ciudadana, en últimas, soporta preguntas que fueron respondidas por la autora para la primera parte del siglo XX, pero que quizá aún tienen vigencia: ¿Quién la invoca? ¿A qué tipo de orden social aspira? ¿Qué tipo de cuerpos produce?

Educar al nuevo príncipe: ¿asunto racial o de ciudadanía?

Autora: Martha Cecilia Herrera

1a. edición, 206 p.

Bogotá: Universidad Pedagógica Nacional, 2013 
